\title{
Práticas ambientalmente sustentáveis em empreendimentos turísticos
}

\author{
Marcelo Pellegrini ${ }^{1}$ \\ Ana Cláudia Machado Padilha² \\ Marcelino de Souza ${ }^{3}$ \\ Submissão: $25 / 08 / 2021$ \\ Aceite: $19 / 10 / 2021$
}

\begin{abstract}
Resumo
As rotas turísticas, especialmente as de alimentos orgânicos, são um fenômeno recente no Brasil, geralmente impulsionadas pela vocação regional de produtores orgânicos que se aliam à demanda de consumidores. No estado do Rio Grande do Sul, no ano de 2016, cria-se a primeira rota de turismo integrada por estabelecimentos que oferecem produtos com certificação orgânica. $O$ objetivo da pesquisa é analisar as práticas ambientalmente sustentáveis (PASs) desenvolvidas nos empreendimentos turísticos que integram a Rota de Turismo Via Orgânica (RTVO). A pesquisa foi descritiva e exploratória, com abordagem qualitativa, com dados coletados por meio de entrevistas realizadas em oito empreendimentos de forma presencial e on-line, via Google Meet. Os resultados foram tabulados e analisados por meio da técnica de análise de conteúdo. Como resultados, observou-se que os empreendimentos turísticos da RTVO adotam PAS que se aliam à preocupação e ao cuidado com o meio ambiente, configurando-se como um diferencial para o público que simpatiza e valoriza a sustentabilidade.
\end{abstract}

Palavras-chave: Agricultura orgânica. Práticas ambientalmente sustentáveis. Rota de Turismo Via Orgânica. Sustentabilidade.

\section{Environmentally sustainable practices in tourist developments}

\begin{abstract}
Tourist routes, especially organic food, are a recent phenomenon in Brazil, generally driven by the regional vocation of organic producers that are allied with consumer demand. In the state of Rio Grande do Sul, in 2016, the first tourism route created by establishments offering products with organic certification is created. The objective of this research is to analyze which are the environmentally sustainable practices (PAS) developed in the tourism enterprises that integrate the Route of Tourism Via Orgânica (RTVO). The method used is descriptive and exploratory, with a qualitative approach, with data collected through interviews conducted in eight enterprises, in person and online, through the Google Meet platform. The interview script was formulated from elements taken from the literature review and the results were tabulated and studied by the content analysis technique. As a result, it was observed that the RTVO tourism enterprises adopt PAS that are allied with the concern and care for the environment, becoming a differential for the public that sympathizes and values sustainability.
\end{abstract}

Keywords: Organic agriculture. Environmentally sustainable practices. Via Orgânica Tourism Route. Sustainability.

\section{Introdução}

Ao longo do tempo, o turismo tem ocupado um papel relevante no desenvolvimento da economia, da mobilidade e da globalização (THENG; QIONG; TATAR, 2015), configurando-se

\footnotetext{
${ }^{1}$ Mestrado em Administração (UPF). ORCID: 0000-0002-7548-8843. E-mail: 150087@upf.br

${ }^{2}$ Doutorado em Agronegócios (UFRGS). Professora do Programa de Pós-Graduação em Administração da Universidade de Passo Fundo (UPF). ORCID: 0000-0002-0701-2640 E-mail: anapadilha@upf.br

${ }^{3}$ Doutorado em Engenharia Agrícola (UNICAMP). Professor dos Programas de Pós-Graduação em Desenvolvimento Rural e em Agronegócio da Universidade Federal do Rio Grande do Sul (UFRGS). ORCID: 0000-0001-6044-6694. E-mail: marcelino.souza@uol.com.br
} 
como um importante fenômeno social, econômico e ambiental, ao incluir em sua essência o deslocamento de pessoas em todo o mundo, impactando significativamente na economia de muitos países (CENAMOR et al., 2017; AZAM; MAHMUDUL ALAM; HAROON HAFEEZ, 2018). Corroborando essa perspectiva, Jackson e Murphy (2006) argumentam que muitos governos já reconheceram o potencial do turismo para alavancar o desenvolvimento econômico regional.

Após anos de crescimento exponencial, o setor do turismo sofre pressões devido à pandemia do novo coronavírus (UNWTO, 2020a). Desse modo, a questão da sustentabilidade ambiental é considerada fator crucial para o desenvolvimento dos empreendimentos (ZENKER; KOCK, 2020), uma vez que o turismo local e de contato com o meio ambiente poderá ser o mais demandado no período pós-pandemia, segundo a pesquisa Cap Amazon e M\&E, realizada com agentes de viagens do Brasil (BRASIL, 2020a). Nesse âmbito, a ideia de conscientização ambiental e desenvolvimento sustentável vem aumentando no setor turístico, devido à complexidade das questões ambientais, à pressão do setor e à preocupação com o cuidado do meio ambiente para as gerações futuras (RICCI; SANT'ANA, 2009; CHAN et al., 2014; ZU'BI et al., 2015; KALLMUENZER et al., 2017).

Entre os desafios enfrentados pela atividade turística, incluem-se as mudanças climáticas e a necessidade de avançar nas práticas ambientalmente sustentáveis (PAS) (BAKOS et al., 2020). Nessa dimensão, o turismo ambientalmente sustentável é capaz de induzir e contribuir para o desenvolvimento local, preservando os recursos naturais, incluindo a comunidade local na atividade econômica, mantendo a conservação do patrimônio histórico-cultural e auxiliando na preservação do meio ambiente (VALVERDE, 2006; FONT; GARAY; JONES, 2014; YUSOF; RAHMAN; IRANMANESH, 2015; MAZHENOVA; CHOI; CHUNG, 2016).

A sustentabilidade ambiental decorre do reconhecimento de que os recursos não são infinitos e leva ao raciocínio de que a degradação desenfreada do meio ambiente prejudicará a vida das gerações futuras (DESAl; DESAI, 2016). Seguindo esse pensamento, muitas empresas vêm adotando políticas ambientais além das obrigações legais como forma de valorizar a sua imagem perante seus stakeholders (FERNANDES; MIRANDA, 2014).

Nessa dinâmica de análise, o turismo não foge à regra. Ele está entre os setores que geram impactos ambientais, como poluição, congestionamento, danificação e superlotação (PEETERS et al., 2018), gerando certa preocupação com seu reflexo ambientalmente negativo em escala internacional (GOSSLING; PEETERS, 2015). Os gestores dos empreendimentos, reconhecendo os impactos que o turismo representa para os ambientes físicos, procuram desenvolver condutas alternativas e mais sustentáveis como solução (COHEN, 2002; STANFORD, 2008). 
Considerando esse contexto, nunca, em tempo algum, foi tão importante propor mecanismos que conciliem as atividades turísticas com o meio ambiente (SAARINEN; GILL, 2018). Cabe a cada organização, ciente do impacto de sua produção no meio ambiente, escolher as práticas ambientais que melhor se adaptem às suas necessidades (SEVERO et al., 2015). Percebese que a implementação de tais práticas está positivamente relacionada à preocupação com os impactos no meio ambiente e à melhoria da imagem do empreendimento perante os usuários e demais stakeholders (EVANGELINOS; HALKOS, 2002).

Dentre os benefícios derivados das PAS's no turismo, podem ser evidenciados os seguintes: conservação dos recursos naturais e dos ecossistemas, restauração de habitats da vida selvagem (ANDRIOTIS; VAUGHAN, 2003; BARBIERI, 2013; CHIN YANG; CHEN, 2008), preservação de paisagens (TARRANT; CORDELL, 2002; TODD; ANDERSON, 2005), aumento da conscientização dos residentes sobre a importância de manter os recursos naturais (CHIN YANG; CHEN, 2008), proteção do meio ambiente, redução de poluentes e conservação do ar e da água (TARRANT; CORDELL, 2002; TODD; ANDERSON, 2005).

Ao considerar a necessidade de preocupação com a sustentabilidade no mundo moderno e ao destacar a sustentabilidade ambiental e a importância da adoção de PAS no contexto do turismo, elegeu-se como objeto de análise desta pesquisa a Rota de Turismo Via Orgânica (RTVO), fundada em 2016 e localizada no município de Garibaldi, no Rio Grande do Sul. Trata-se de rota turística pioneira no Brasil por explorar como atrativos a produção, a industrialização, a comercialização e o consumo de alimentos orgânicos certificados, sendo constituída por nove empreendimentos integrantes.

A pesquisa tem como objetivo particular analisar as práticas ambientalmente sustentáveis desenvolvidas nos empreendimentos turísticos que integram a Rota de Turismo Via Orgânica. A proposta da RTVO é valorizar o estilo de vida que alia o alimento à saúde e à sustentabilidade ambiental, social e cultural, por meio da visitação a propriedades orgânicas certificadas com produção agroecológica e artesanal.

\section{Revisão da Literatura}

2.10 conceito de sustentabilidade e a dimensão ambiental no turismo

Fatores como a Revolução Industrial, a diferença de padrões de vida e de consumo na sociedade e o aumento da população motivaram o surgimento de movimentos que enfatizam 
políticas socioeconômicas em busca da não degradação ambiental (POTT; ESTRELA, 2017). Segundo Abramovay (2012, p. 16), "a ideia de crescimento incessante da produção e do consumo choca-se contra os limites que os ecossistemas impõem à expansão do aparato produtivo".

A partir dessas percepções, diversos pesquisadores passaram a estudar formas de redução dos impactos sobre o meio ambiente, posto que a crise ambiental passou a apresentarse como fator limitante do crescimento econômico e populacional (JONES; HILLIER; COMFORT, 2016). Por volta de 1960, surgiram as primeiras reflexões e debates a respeito do meio ambiente e da sustentabilidade, quando alguns países afirmavam que a problemática ambiental havia sido inventada pelos países desenvolvidos, para frear a ascensão dos países subdesenvolvidos (CLARO; CLARO; AMÂNCIO, 2008). Daquele momento em diante, a preocupação com o meio ambiente passou a fazer parte dos meios políticos e das estratégias organizacionais, pois, de uma forma ou de outra, possibilitava ou limitava o desenvolvimento (SANCHES, 2015).

A importância da preservação ambiental para o desenvolvimento do turismo foi reconhecida pela Organização Mundial do Comércio (OMC) na década de 1970, com a criação de um Comitê de Meio Ambiente e a Conferência das Nações Unidas sobre o Meio Ambiente e o Desenvolvimento (CNUMAD), também conhecida como ECO-92, que identificou o turismo como uma das áreas prioritárias para o desenvolvimento sustentável. A partir desse momento, ações em prol do meio ambiente passaram a ganhar impulso e reconhecimento dentro da indústria da hotelaria (MEBRATU, 1998; KOROSSY, 2008; BOHDANOWICZ, 2006).

O conceito de desenvolvimento sustentável (DS) surgiu oficialmente em 1987, por meio do relatório "Nosso Futuro Comum", elaborado pela Comissão Mundial sobre Meio Ambiente e Desenvolvimento (CMMAD) (1988), conhecido igualmente por Relatório Brundtland (SANTOS; BERNARDES, 2019). De acordo com o documento, DS “é aquele que atende às necessidades do presente sem comprometer a possibilidade das gerações futuras de atenderem às próprias necessidades" (CMMAD, 1988, p. 46).

No ano de 1992, a realização da II Conferência das Nações Unidas para o Meio Ambiente e Desenvolvimento (Rio-92), realizada na cidade do Rio de Janeiro, marcou o início da fase das discussões ambientalistas acerca da gestão ambiental global (BARBIERI, 2004). Anos depois, em 2002, foi realizada, na cidade de Johanesburgo, na África do Sul, a Rio+10; mais tarde, em 2012, na cidade do Rio de Janeiro, aconteceu a Rio+20, seguindo com o debate a respeito da sustentabilidade ambiental em nível mundial (GUIMARAES; FONTOURA, 2012; BARBIERI, 2004; FREY; CAMARGO, 2003; MEBRATU, 1998). 
No ano de 2015, durante a Cúpula das Nações Unidas, foram propostos, por líderes mundiais, os 17 Objetivos de Desenvolvimento Sustentável (ODS), os quais contam com uma rede multidisciplinar de apoio e parcerias, entre diferentes entes, para que sejam alcançados. Entre os 17 ODS, estão: acabar com a pobreza, combater a desigualdade e a injustiça e resolver as mudanças climáticas até 2030 (GUPTA; VEGELIN, 2016; JAYASOORIA, 2016). Nessa dimensão, o turismo tem um papel de destaque em razão de sua relevância econômica, pois representa cerca de $10 \%$ do produto interno bruto (PIB) e do emprego do mundo. Esse cenário faz com que a atividade seja essencial para o avanço dos ODS (BRASIL, 2018).

O conceito de sustentabilidade vem ganhando maior visibilidade nos últimos anos (BOLIS; MORIOKA; SZNELWAR, 2014), pois, para se viver de uma maneira sustentável, é necessário assegurar que os recursos e os serviços da natureza sejam utilizados de maneira que permitam a sua regeneração. Nesse contexto, as práticas ambientalmente sustentáveis (PAS) surgem como alternativa para a conservação do meio ambiente (SKIBINS; POWELL; HALLO, 2013).

Barbieri (2011) afirma que a sustentabilidade retrata a qualidade daquilo que é sustentável, ou seja, ela incorpora o significado de manutenção e conservação dos recursos naturais. Trata-se de compreender a importância de equilibrar as necessidades ambientais, econômicas e sociais na vida das sociedades, não fazendo sentido pensá-las como concorrentes eternas, e sim como partes inseparáveis de um todo (ELKINGTON, 2012). A Avaliação Global da Plataforma Intergovernamental sobre Biodiversidade e Serviços Ecossistêmicos (IPBES) enfatizou a necessidade de uma transformação e da integração de valores ambientalmente sustentáveis para a promoção de mudanças positivas em direção à sustentabilidade (DIAZ et al., 2019).

No setor do turismo, a exploração depende da gestão, podendo se caracterizar como uma atividade de promoção ou destruição do meio ambiente (SANTOS; BERNARDES, 2019). Segundo Pellegrini (2000), todo efeito ou alteração no meio ambiente ou em algum de seus componentes por determinada ação ou atividade é considerado um impacto. Conforme as modificações produzidas e os eventos posteriores, podem-se avaliar como impactos positivos ou negativos. Em relação aos impactos positivos da atividade do turismo sobre o meio ambiente, é possível citar benefícios como criação de programas de preservação das áreas naturais, investimento em medidas preservacionistas, valorização do contato com a natureza e utilização mais consciente dos espaços naturais (RUSCHMANN, 1997). Quanto aos impactos negativos, podem ser referidos: destruição das áreas naturais, da fauna e da flora, mudança da paisagem em decorrência da construção de equipamentos e infraestrutura turística, pisoteio da vegetação, vandalismos, incêndios, poluição das águas, acúmulo de detritos, poluição visual, sonora e atmosférica 
(RUSCHMANN, 1997; KO; STEWART, 2002; GURSOY; RUTHERFORD, 2004; REICHERT; LANZER, 2015).

A sustentabilidade pode se apresentar como uma prática de diminuição dos impactos negativos provindos do turismo contra o meio ambiente (RUSCHMANN, 1997). Ressalta-se que as demandas ambientais e sociais se apresentam com características importantes, em razão dos impactos que apresentam na qualidade de vida dos indivíduos pertencentes à sociedade moderna (RUSCHMANN, 1997). A sustentabilidade se configura como importante estratégia para diminuição de impactos sociais e ambientais oriundos dos processos produtivos, pois ela permite resolver as contradições entre o crescimento econômico, a distribuição de renda e a necessidade de conservar os recursos ambientais, em benefício não somente das gerações atuais, mas também das futuras (DIEGUES, 2003).

O Ministério do Turismo (BRASIL, 2010a) apontou como elemento orientador de suas ações estratégicas a relação entre o turismo e a sustentabilidade, que deveria seguir os princípios da sustentabilidade ambiental, econômica, sociocultural e político-institucional. Dessa forma, com o objetivo de desenvolver produtos turísticos sustentáveis em consonância com o meio ambiente e a cultura local, fazendo com que as comunidades locais deixem de ser meramente espectadores privilegiados do processo de estruturação do setor turístico, foi implementado no Brasil o conceito de turismo sustentável, criado pela OMT: "Turismo sustentável é a atividade que satisfaz as necessidades dos turistas e as necessidades socioeconômicas das regiões receptoras, enquanto a integridade cultural, a integridade dos ambientes naturais e a diversidade biológica são mantidas para o futuro" (BRASIL, 2010b, p. 30).

Na declaração final da Rio+20 (ONU, 2012), foi estipulado que o turismo sustentável deve promover consciência ambiental, conservando o meio ambiente, a biodiversidade, os ecossistemas e a diversidade cultural, melhorando o bem-estar das comunidades locais (GUIMARAES; FONTOURA, 2012). Contudo, a conscientização da sustentabilidade para os atores da indústria do turismo é um processo complexo e de longo prazo, visto que compete a cada empresa esforçar-se no sentido de cumprir a sua parte em um contexto de responsabilidade com a sociedade e o meio ambiente. Portanto, faz-se necessário o diálogo constante entre empresários e representantes do turismo e da comunidade local (BARBIERI, 2011).

Para Dias e Pimenta (2005), é necessário romper a barreira da individualidade para atentar ao comportamento sistêmico do ambiente de uma forma geral. A relevância da discussão de temas como responsabilidade social corporativa e sustentabilidade no setor turístico está relacionada às transformações e aos impactos da sustentabilidade (BARBIERI, 2011). Existe uma 
pressão para que os empreendimentos turísticos contribuam para a valorização da cultura local, o respeito ao meio ambiente e a geração de emprego e renda da comunidade na qual estão inseridos (COELHO; GOSLING; GONÇALVES, 2013).

Pesquisa realizada com clientes de hotéis na Europa apontou para a importância da adoção de PAS, dado que muitos clientes escolheram tais hotéis como destinos devido à sua preocupação com o meio ambiente (BEREZAN et al., 2013). Alguns estudos indicam que os ecoturistas estão dispostos a pagar mais quando o produto da sua experiência contribuirá para as comunidades locais ou contribuirá diretamente para a conservação da biodiversidade da região (BARAL, STERN; BHATTARAI, 2008; WANG; JIA, 2012).

A evolução da consciência ambiental e, consequentemente, a preocupação com os possíveis impactos negativos ao meio ambiente, se consolidaram por meio de um termo específico denominado "turismo sustentável" (VALVERDE, 2006). Para Swarbrooke (2000), apesar de a expressão "turismo sustentável" ter sido usada inicialmente a partir do final da década de 1980, quando estudiosos da época começaram a levar em consideração as implicações do Relatório Brundtland, foi no início da década de 1990 que ela passou a ser usada com frequência.

A Organização das Nações Unidas proclamou 2017 como o Ano Internacional do Turismo Sustentável, em reconhecimento ao potencial do setor para contribuir com a redução da pobreza, a promoção do entendimento entre os povos, o respeito às diferentes culturas e a preservação dos recursos naturais (UNESCO, 2017). Dulley (2004) definiu os recursos naturais como aqueles que estão disponíveis no ambiente físico (a terra, o ar, a água, a vegetação, a vida selvagem), onde existem para satisfazer as necessidades do homem.

A OMT (2003, p. 172) afirma que "o ambiente físico é um recurso turístico importante e, desde a época de Roma e a Grécia antiga, os viajantes têm sido motivados por um desejo de experimentar diversos de seus aspectos". À vista disso, percebe-se que as pessoas começaram a turistar desde a antiguidade, e os recursos naturais têm se apresentado como ferramentas de atração turística, motivando milhares de viagens ao redor do mundo (MACEDO, 2011).

Para o desenvolvimento da atividade turística, pode-se fazer necessária a utilização dos recursos naturais, obtendo-se um diferencial turístico (MACEDO, 2011). Com base em Beni (2007), verifica-se que os recursos naturais existentes possuem características relevantes para o turismo, como: vegetação, fauna, locais de interesse de visitação, qualidade da água, praias, falésias, baías, rios, características da paisagem circundante e conformação geológica e morfológica. Esses recursos servem de atrativos para os visitantes de determinada localidade, 
sendo que devem ser levados em consideração, de forma a buscar conservá-los para que a atividade turística continue a trazer benefícios tanto para as gerações presentes como para as vindouras (MACEDO, 2011).

Nessa perspectiva, é possível observar que o ambiente físico no turismo deve ser mantido como fator fundamental para o sucesso de um destino, baseado na qualidade ambiental, uma vez que os destinos que são vistos como poluídos ou congestionados terão dificuldades em manter a atividade turística, podendo entrar em declínio (OMT, 2003). De fato, os recursos naturais podem ser determinantes para o desenvolvimento do turismo, pois a qualidade do ambiente e sua preservação corroboram essa perspectiva. Desse modo, a questão da sustentabilidade vem ao encontro do que é proposto neste estudo, as PAS podem auxiliar na preservação e no cuidado com o meio ambiente.

\subsection{Práticas ambientalmente sustentáveis no turismo}

A adoção de PAS envolve o ato e o processo de ser capaz de renovar recursos, reduzir a poluição e eliminar processos que prejudicam o meio ambiente (BAKOS et al., 2020). Adotá-las em empreendimentos turísticos nem sempre exige investimento, é um diferencial que, na maioria dos casos, decorre de processos simples empregados na rotina das organizações, como resultados de projetos bem-sucedidos, em organizações de pequeno, médio e grande porte, tudo de acordo com sua estrutura (SILVA et al., 2016).

No ano de 2010, foi sancionada a lei que instituiu a Política Nacional de Resíduos Sólidos (PNRS), a Lei no 12.305 (BRASIL, 2010a), a qual contém instrumentos importantes para permitir o avanço necessário do Brasil no enfrentamento dos principais problemas ambientais, sociais e econômicos decorrentes do manejo inadequado dos resíduos sólidos (DEMAJOROVIC; MIGLIANO, 2013).

Com a Política Nacional de Resíduos Sólidos, destacam-se a educação ambiental, a responsabilidade compartilhada pela destinação correta dos resíduos por meio da logística reversa, o processo de coleta das embalagens após o consumo para serem reaproveitadas nas indústrias no mesmo ou em outros ciclos produtivos, o incentivo à criação e ao desenvolvimento de cooperativas ou de outras formas de associação de catadores de materiais reutilizáveis e recicláveis (BRASIL, 2010a). Os resíduos sólidos são um dos principais contribuintes para as emissões de gases de efeito estufa (GEE) em todo o mundo e sempre um participante importante 
nos planos e nas iniciativas de mitigação dessas emissões (ABU HAJAR et al., 2020; BONG et al., 2017; DEDINEC et al., 2015).

Por intermédio da reciclagem, existe a preocupação em minimizar os danos ambientais. Ela abrange um sistema participativo de gestão que inclui as alternativas social, econômica e ambiental e precisa de certo investimento de tempo do sujeito ao proceder à separação do material descartado para o retorno ao processo industrial (GARCIA et al., 2016). As leis e normativas trazem uma bonificação ou redução de impostos para as organizações que reciclam os resíduos produzidos (WAN; SHEN; CHOI, 2017). O sucesso da reciclagem depende do comprometimento e do envolvimento do público e da comunidade, bem como da disponibilidade e da infraestrutura de equipamentos para reciclar e coletar (TROSCHINETZ; MIHELCIC, 2009).

Entre outros métodos, a compostagem se apresenta como prática conhecida para estabilizar e reduzir o volume de resíduos orgânicos, resultando em fertilizantes orgânicos (ABU HAJAR et al., 2020). Alternativas como essa não apenas criam oportunidades reais de emprego, como também apresentam um potencial para integrar o setor de reciclagem informal nas atividades de recuperação de materiais (ALARADIN; PERSSON; SOOD, 2015).

Blancas et al. (2010) asseguram que a proteção dos recursos naturais se garante a partir da proteção dos ecossistemas naturais, os quais estão dentro de áreas naturais protegidas dos destinos turísticos, de modo que a intensidade do uso turístico dessas áreas deve ser controlada. Dentre os recursos existentes, deve-se tomar um maior cuidado com os recursos naturais escassos, como a água, por exemplo, que é essencial para a sobrevivência dos seres vivos e, do mesmo modo, um fator de produção para os bens de consumo, além de ser um elemento representativo de valores sociais e culturais (GOMES, 2011). Além da higiene e da produção de alimentos, o uso da água no turismo é essencial para: recreação, paisagismo, esportes, entre outras atividades relacionadas (GOSSLING, 2015; HADJIKAKOU; CHENOWETH; MILLER, 2013; TORTELLA; TIRADO, 2011).

As atividades da sociedade moderna requerem o uso de uma ou mais fontes de energia, para tal, um aspecto que tem se revelado importante é a eficiência energética, que consiste em obter o melhor desempenho da produção de um bem ou serviço com o menor consumo de energia possível (BRASIL, 2016). Por isso, a melhoria da eficiência energética dos sistemas produtivos é fundamental para o desenvolvimento sustentável, pois agrega ganhos sociais, ambientais e competitivos, ensejando medidas governamentais em médio e longo prazos em 
todos os setores (GELLER et al., 2004). O quadro 1 pode auxiliar na verificação das Práticas Ambientalmente Sustentáveis (PASs) que podem ser adotadas em empreendimentos turísticos.

Quadro 1 - PAS em empreendimentos turísticos da Rota Via Orgânica.

\begin{tabular}{|c|c|}
\hline PRÁTICAS & FONTES \\
\hline $\begin{array}{l}\text { Gestão de resíduos sólidos } \\
\text { Reciclagem } \\
\text { Compostagem }\end{array}$ & $\begin{array}{l}\text { Brasil (2010); Abu Hajar et al. (2020); Mansour, Al- } \\
\text { yahyai e Heiba (2018); Bong et al. (2017); Dedinec et } \\
\text { al. (2015); Aljaradin, Persson e Sood (2015); } \\
\text { Demajorovic e Migliano (2013) }\end{array}$ \\
\hline $\begin{array}{l}\text { Eficiência energética } \\
\text { Fontes alternativas de energia } \\
\text { Redução, desperdício de energia elétrica }\end{array}$ & $\begin{array}{l}\text { Dyatlov et al. (2020); Martinez et al. (2009) } \\
\text { Dale (2013); Geller et al. (2004) }\end{array}$ \\
\hline Uso racional da água & $\begin{array}{l}\text { Silva e Mattos (2020); Gossling (2015); Hadjikakou, } \\
\text { Chenoweth e Miller (2013); Tortella e Tirado (2011); } \\
\text { Gomes (2011) }\end{array}$ \\
\hline $\begin{array}{l}\text { Proteção dos recursos naturais } \\
\text { Gestão de recursos naturais escassos } \\
\text { Gerenciamento do impacto visual e da } \\
\text { infraestrutura }\end{array}$ & Blancas et al. (2010) \\
\hline Preservação da paisagem natural & Butler (1999) \\
\hline Manejo biológico de pragas & Choo e Jamal (2009) \\
\hline $\begin{array}{l}\text { Agricultura sustentável } \\
\text { Produção de orgânicos } \\
\text { Certificação de orgânicos } \\
\text { Preservação do solo, } \\
\text { Embalagens sustentáveis } \\
\text { Qualidade do ar }\end{array}$ & $\begin{array}{l}\text { Radomsky (2009); lannone et al. (2016); Brantsaeter } \\
\text { et al. (2017); Ivanov e Ziganshin (2018); Martins et } \\
\text { al. (2018); Lazaroiu et al. (2019); Ferreira, Silva e } \\
\text { Madeira (2019); Abu Hajar et al. (2020) }\end{array}$ \\
\hline
\end{tabular}

Fonte: Elaborado pelos autores (2021).

A economia de energia com redução de desperdício é um fator que garante a economia de recursos financeiros destinados a aumentar a escala de produção de energia e sua importação (DYATLOV et al., 2020). A preocupação com a redução do consumo e o uso racional de energia elétrica no Brasil tem aumentado devido a dois fatores principais: o aumento de tarifa com as mudanças estruturais do setor elétrico e a preocupação em reduzir os impactos ambientais e incentivar energias alternativas (MARTINEZ et al., 2009). Entre as tecnologias ambientais energéticas que mais se destacam estão as energias solar e eólica. Essas novas fontes de energia têm maior potencial de se tornarem custos competitivos com as outras fontes de energia e são as que mais provavelmente contribuirão rapidamente para a mitigação das mudanças climáticas 
(DALE, 2013; IEA, 2017). Elas também auxiliam o desenvolvimento de empreendimentos turísticos, visto que é perceptível a redução do custo da energia (DYATLOV et al., 2020).

O número de visitantes em determinado local exige e resulta no estabelecimento de instalações e infraestrutura para atender às suas necessidades; como resultado, as áreas naturais perdem parte de sua naturalidade e, portanto, atratividade (AZAM; MAHMUDUL ALAM; HAROON HAFEEZ, 2018). À medida que aumenta o número de instalações turísticas, o mercado muda, e muitos visitantes que foram atraídos pelas características do ambiente e pela ausência de desenvolvimento optam por escolher outros locais com preservação da paisagem natural (BUTLER, 1999).

Pode-se perceber que a preservação do ambiente em que o empreendimento está localizado é aliada ao seu desenvolvimento, exemplos disso são a produção e a comercialização de alimentos orgânicos (PROVOST; PEDNEAULT, 2016; SACCHELLI et al., 2017). A produção de orgânicos se insere como objeto de estudo neste artigo, o qual será debatido na próxima sessão.

\section{Procedimentos metodológicos}

A pesquisa caracteriza-se por uma abordagem qualitativa, tendo em vista que a "pesquisa qualitativa não se preocupa com representatividade numérica, mas, sim, com o aprofundamento da compreensão de um grupo social, de uma organização" (MINAYO, 2001, p. 316. Trata-se de uma pesquisa descritiva, seguindo os parâmetros propostos por Gil (1999), uma vez que se buscou identificar quais são as PAS implementadas/utilizadas em empreendimentos (por atores) que integram a RTVO. Também se classifica como descritiva/exploratória, por proporcionar maior familiaridade com o tema, visto que se busca compreender um fenômeno pertinente para o campo do turismo, visto que não foi encontrado nenhum trabalho a respeito de PAS's na RTVO. Os estudos exploratórios justificam-se pelo desconhecimento acerca de uma questão de pesquisa levantada pelo pesquisador, e seu objetivo reside, essencialmente, no conhecimento do tema ou problema de pesquisa (MATTAR, 1994; ROESCH, 1996)

Foram pesquisados oito empreendimentos, visto que um não aceitou participar. A compreensão surgiu a partir da análise dos dados obtidos dos entrevistados e da experiência do entrevistador durante a coleta dos dados, que foi presencialmente nos empreendimentos cujos entrevistados não eram dos grupos de risco para a Covid-19 e por meio do Google Meet para os pertencentes aos grupos de risco. $\mathrm{O}$ instrumento de coleta de dados foi um questionário com 
perguntas abertas os quais os entrevistados puderam destacar as principais PAS desenvolvidas nos empreendimentos.

As respostas foram gravadas em áudio, degravadas e tabuladas no software Excel. De posse dos dados, a técnica escolhida foi a análise de conteúdo, organizada em três etapas: a préanálise, a exploração do material, o tratamento dos resultados e as interpretações (Bardin, 2009). Os resultados e sua análise serão apresentados na próxima seção deste artigo.

\section{Resultados e discussões}

\subsection{Caracterização da RTVO}

A RTVO localiza-se no município de Garibaldi, na Serra Gaúcha, no estado do Rio Grande do Sul, a 110 quilômetros da capital, Porto Alegre. O município conta com uma população de 35.440 habitantes, pertence à Primeira Colônia da Imigração Italiana e integra a Região Turística Uva e Vinho e o Vale dos Vinhedos, sendo reconhecido como a "Capital Brasileira do Espumante", devido ao pioneirismo e à qualidade de seus vinhos e espumantes (SCHERER et al., 2017).

Com o propósito de diversificar ainda mais a oferta do turismo e da gastronomia, o município de Garibaldi desenvolveu a RTVO, lançada em outubro de 2016, com uma proposta focada no turismo voltado para gastronomia, cultura e sustentabilidade. O projeto foi desenvolvido a partir de uma iniciativa conjunta entre o Serviço Brasileiro de Apoio às Micro e Pequenas Empresas (Sebrae/RS) e a Secretaria Municipal de Turismo de Garibaldi, com o objetivo de criar um destino turístico específico de espaços que cultivem ou revendam produtos orgânicos certificados.

Em reuniões realizadas no município, ficou acordado que os membros deveriam possuir empreendimentos localizados nos limites de Garibaldi e serem certificados como produtores orgânicos pelos órgãos responsáveis (PADILHA; DE SÁ; RODRIGUES, 2018). Na rota, o turista encontra paisagens, resgate de antigas formas de cultivo aprimoradas pelas novas tecnologias e pela preocupação com a sustentabilidade, contato direto com a simplicidade e a experiência de quem produz e prepara o alimento (SCHERER et al., 2017).

Atualmente, a RTVO abarca nove empreendimentos que se destinam a produção, industrialização e comercialização de orgânicos, bem como a hospedagem e visitas guiadas. Desses, oito participaram desta pesquisa. 
De acordo com os entrevistados, a RTVO tornou-se um importante elo de ligação entre os empreendimentos e os turistas, uma vez que a procura por alimentos orgânicos aumentou consideravelmente nos últimos cinco anos.

O Sítio Crescer está localizado a menos de cinco quilômetros do centro de Garibaldi e cultiva hortaliças, temperos e frutas, a partir da produção orgânica. Na propriedade localiza-se um hostel (hospedagem compartilhada), estruturado a partir de uma construção sustentável; os materiais que configuram o telhado são feitos de embalagens tetrapak reutilizadas. Além dos quartos compartilhados, existe a possibilidade de hospedagem em quartos individuais. São oferecidos também espaços para a realização de eventos, açudes para banho e pesca, "Sítio Tour" (visita guiada na propriedade, onde os visitantes conhecem a propriedade de trator).

A Orgânicos Mariani, é gerenciada pela família que se dedica à produção orgânica desde 1998, onde cultiva diferentes tipos de frutas. O empreendimento produz vinhos, sucos, geleias e molhos, todos provenientes do método de produção orgânico certificado. Como atrativo turístico, o visitante pode realizar passeio de trator, com vista panorâmica, colher frutos e temperos, de acordo com a sazonalidade, no local são comercializados também produtos orgânicos produzidos pelo empreendimento.

A loja Davida Orgânicos oferece, de forma exclusiva, conforme informações dos proprietários, lanches e almoços com opções de alimentos de produções orgânicas. Dispõe de um espaço para cursos e oficinas culinárias, com o objetivo de educar e promover a saúde. Neste mesmo local, também há um comércio especializado em alimentos naturais e orgânicos de venda direta ao consumidor.

A loja Sabor Ecológico é administrada pelos próprios proprietários, um agricultor e uma nutricionista. O comércio de alimentos é especializado em produtos naturais e orgânicos e tem como objetivo transmitir a impressão e a credibilidade de ofertar alimentos orgânicos e frescos, em meio ao espaço urbano, no centro da cidade. No local, são comercializados hortaliças, legumes, frutas, sucos, geleias, molhos, chás, açúcar, café, farinhas, grãos, sendo eles todos cultivados a partir de processos e métodos de produção orgânica certificada. Além destes produtos naturais, os proprietários comercializam produtos para dietas restritivas, como linhas de produtos naturais, sem glúten, sem lactose, dietéticos e fitoterápicos.

Pertencente também à RTVO a Cooperativa Vinícola Garibaldi é uma sociedade de produtores, que não têm apelo ao orgânico, mas sim à vitivinícola, tendo um nicho de mercado a produção orgânica. Atualmente, composta por 400 famílias associadas, encontra-se no centro de Garibaldi. Somando os espaços de produção, são cultivados 1000 hectares de vinhedos. A 
Cooperativa, desta maneira, desponta na produção orgânica e biodinâmica com certificação internacional, sendo pioneira no Brasil.

Outro empreendimento é a Econatura, construída com materiais de reuso, tanto a estrutura física, quanto os maquinários utilizados para extração dos produtos. A partir da uva, trabalha de maneira que se minimizem os impactos ambientais. A propriedade possui um espaço denominado espaço "Ecopipa", que é utilizado como área para degustação dos produtos comercializados em lojas e supermercados de todo o Brasil. A fábrica produz suco de uva, vinagres de vinho tinto, balsâmico e balsâmico envelhecido, vinagre de maçã e óleo de semente de uva, farinha da semente e da casca de uva, todos orgânicos. Em Garibaldi, os produtos podem ser adquiridos nas lojas Sabor Ecológico e Davida Orgânicos.

Outro empreendimento é o da Família Boroto, o qual dedica-se à elaboração de espumantes e vinhos orgânicos. Na propriedade pode ser realizado um passeio em meio aos parreirais e, após, usufruída uma degustação dos produtos, harmonizados com tábua de frios, chamada de meredin perlage. Outra possibilidade de atividade, que poderá ser realizada pelo visitante, é a apresentação dos processos de produção do espumante. O proprietário afirma que, além das atrações no local, os turistas poderão realizar passeios às grutas e a capitéis próximos da propriedade, repletos de histórias.

O Sítio do Celo oferece o apreço de uma paisagem silvestre; o local possui diversas plantas nativas e frutas exóticas. Também são cultivadas frutas da época, que podem ser degustadas e adquiridas pelos visitantes. O empreendimento oferece uma degustação do caldo de cana (garapa) feito na hora. O intuito deste local é poder proporcionar momentos de tranquilidade, a partir da paisagem e calmaria ou realizar uma inspiradora trilha com um caminho meditativo até um riacho.

É importante salientar que a região possui uma boa infraestrutura local para atender os visitantes, como estradas de acesso em boas condições, em sua maior parte com calçamento de paralelepípedos ou asfalto. Os empreendimentos, exceto um, contam com internet de fibra ótica de boa qualidade e a energia oferecida, segundo os entrevistados, também é de boa qualidade.

\subsection{Práticas Ambientalmente Sustentáveis desenvolvidas nos empreendimentos}

Os empreendimentos da RTVO buscam, desde a sua formação, o cuidado com a preservação do meio ambiente, por intermédio da certificação orgânica. Seus representantes 
descrevem que seus empreendimentos estão sempre preocupados com as questões ambientais, e os turistas que visitam a rota valorizam essas questões.

Nesta etapa da coleta de dados, questionaram-se os entrevistados sobre assuntos ligados às PASs (Gráfico 1). As principais PASs desenvolvidas nos empreendimentos da RTVO são: gestão de resíduos sólidos; reciclagem; eficiência energética; redução do desperdício de energia elétrica; e uso racional da água. É possível verificar que as práticas que são desenvolvidas em sua totalidade não necessitam de alto custo de investimento e são de fácil implementação. Isso vai ao encontro dos resultados observados em Bakos et al. (2020), o qual destaca que grande parte de práticas ambientalmente sustentáveis não necessitam alto custo de investimento.

De oito empreendimentos pesquisados, sete destinam os resíduos orgânicos para fins de compostagem. Eles responderam que utilizam os restos de alimentos na compostagem com a finalidade de adubação e melhoria na matéria orgânica do solo. Isso está alinhado com os pressupostos de Hajar et al. (2020), os quais mencionam que a adubação orgânica, proveniente de compostagem, auxilia na nutrição do solo.

Gráfico 1 - PASs desenvolvidas nos empreendimentos da RTVO

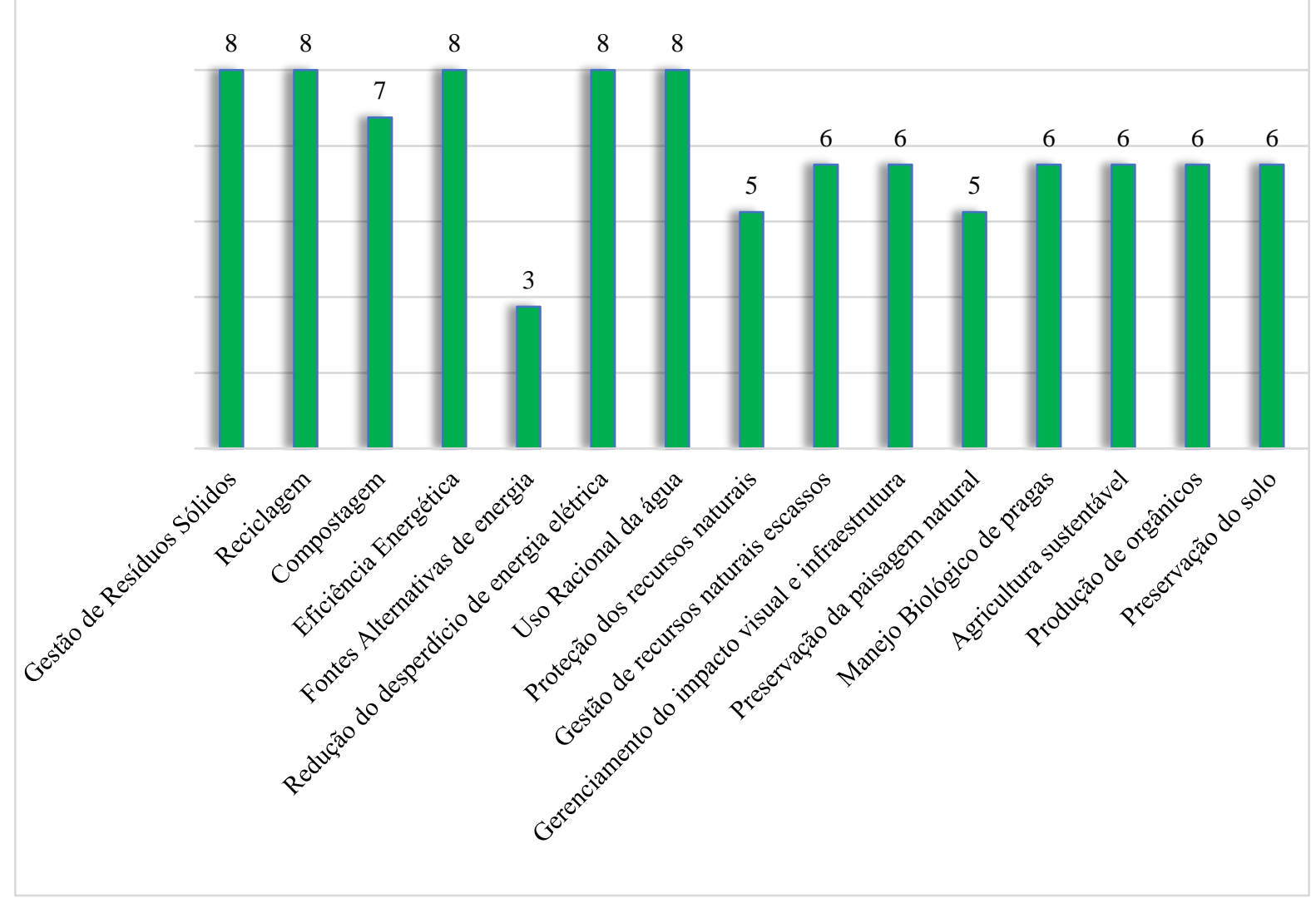

Fonte: Dados da pesquisa (2021).

Durante as entrevistas, seis participantes relataram que desenvolvem a gestão de recursos naturais escassos, como diminuição do uso de água, preservação do solo e preservação 
dos habitats de espécies silvestres. Isso corrobora o retratado por Silva e Mattos (2020), de que a preservação dos recursos naturais escassos é fator determinante para sua renovação.

Todos os entrevistados relataram que procuram fazer um melhor gerenciamento do impacto visual e da infraestrutura, evitando obras de grande porte que possam degradar o meio ambiente. Eles desenvolvem a agricultura sustentável e a produção orgânica, bem como o manejo biológico de pragas, o qual evita a utilização de agroquímicos e desenvolve a preservação do solo com a adubação verde e orgânica. Igualmente, cinco pesquisados relataram que promovem a proteção dos recursos naturais com a preservação de nascentes de água e procuram manter áreas nativas em seus empreendimentos, procurando preservar a paisagem natural e evitando obras de grande porte que possam intervir na paisagem natural.

A implementação de fontes alternativas de energia é a prática menos desenvolvida na RTVO, visto que apenas três empreendimentos possuem mecanismos de produção de energia renovável. Os entrevistados retrataram como justificativa o alto custo financeiro para sua instalação. O estudo de Kallmuenzer et al. (2017) também retrata que muitos empreendimentos resistem em adotar algumas PAS devido ao seu alto custo de implementação.

\section{Considerações Finais}

Esta pesquisa dedicou-se a analisar as práticas ambientalmente sustentáveis desenvolvidas nos empreendimentos turísticos que integram a Rota de Turismo Via Orgânica. Pode-se perceber que os empreendimentos turísticos da adotam PAS's de acordo com cada realidade, uma vez que alguns se dedicam à produção e à comercialização de orgânicos, enquanto dedicam-se a hospedagens e às visitas guiadas. Dentre as principais práticas desenvolvidas, destacam-se: gestão de resíduos sólidos, reciclagem, eficiência energética, redução do desperdício de energia elétrica e uso racional da água.

Partindo das entrevistas realizadas, pode-se afirmar que os gestores dos empreendimentos turísticos percebem que a adoção de PAS tem importância, pois permitem a diminuição de gastos e a produção de produtos orgânicos. Além disso, a sustentabilidade é algo que deve ser levado em consideração, visto que, atualmente, os turistas têm preocupação e cuidado com o meio ambiente, o que se torna um diferencial para os empreendimentos que integram a rota pesquisada. Ressalta-se que, de maneira geral, as iniciativas de sustentabilidade ambiental praticadas nos destinos analisados são realizadas de forma individual, sendo que cada 
empreendimento realiza as atividades que entendem ser necessárias, sem que haja auxílio mútuo e/ou troca de informações e ideias entre si.

Como contribuição significativa da pesquisa para a sociedade, fica evidente que tal iniciativa de criação uma rota turística voltada para produtos orgânicos certificados, pode inspirar e motivar outros projetos nessa mesma proposta. Não somente isso, a crescente exigência de turistas por inovações no setor, também pode configurar-se como uma alternativa importante de revitalização e ampliação da demanda pós-pandemia.

Algumas limitações podem ser mencionadas com relação à pesquisa. A principal foi o impedimento de realização da pesquisa presencialmente, na maioria dos empreendimentos, foi o impedimento de coleta de dados presencialmente sem vivenciar o ambiente turístico nos empreendimentos. Portanto, os resultados limitam-se aos casos abordados, não podendo ser generalizados para toda a rota de turismo, observando que, após a pandemia da Covid-19, os dados podem se revelar diferentes. Quanto às implicações gerenciais, os resultados mostraram a importância de desenvolver PAS's que contribuam para a preservação do meio ambiente e o diferencial que isso implica na atuação turística.

Como sugestão de pesquisas futuras, recomenda-se a ampliação para a avaliação na dimensão dos turistas que visitam os empreendimentos, capturando suas percepções com relação às Práticas Ambientalmente Sustentáveis (PAS's) adotadas em cada empreendimento visitado. Outra possibilidade interessante é dedicar atenção de pesquisa da temática para outras rotas turísticas, avaliando quais seriam os entraves e oportunidades de adoção dessa lógica enquanto estratégia de desenvolvimento e promoção do turismo em diferentes regiões.

E para finalizar, percebe-se que a temática instigante que discute as PAS's consolida-se como uma possibilidade em termos de competitividade do turismo, especialmente por apontar benefícios que alcançam para uma melhoria e redução de custos inerentes à atividade de produção, industrialização e comercialização de produtos alimentícios, preservação do meio ambiente, cuidado com a saúde, produção e consumo de alimentos orgânicos, qualidade de vida para as famílias que atuam nesses empreendimentos, motivação para continuar na atividade, desenvolvimento de novas inovações e, especialmente, o reconhecimento da sociedade que, de fato, é possível incorporar um novo olhar para o setor de turismo que possui significativas possibilidades contribuir para a geração de riqueza e desenvolvimento de comunidades locais. 


\section{Referências}

ABU HAJAR, H. A.; TWEISSI, A.; ABU HAJAR, Y. A.; AL-WESHAH, R.; SHATANAWI, K. M.; IMAM, R.; ABU HAJER, M. A. Assessment of the Municipal Solid Waste Management Sector Development in Jordan towards Green Growth by Sustainability Window Analysis. Journal of Cleaner Production, v. 120539, 2020.

ALARADIN, M.; PERSSON, K.; SOOD, E. The role of informal sector in waste management, a case study. Tafila-Jordan Resources and Environment, v. 5, n. 1, p. 9-14, 2015.

ANDRIOTIS, K.; VAUGHAN, R. Urban residents' attitudes toward tourism development: the case of Crete. Journal of Travel Research, v. 42, n. 2, p. 172-185, 2003.

AZAM, M.; MAHMUDUL ALAM, M.; HAROON HAFEEZ, M. Effect of tourism on environmental pollution: further evidence from Malaysia, Singapore and Thailand. Journal of Cleaner Production, v. 190, p. 330-338, 2018.

BAKOS, J.; SIU, M.; ORENGO, A.; KASIRI, N. An analysis of environmental sustainability in small \& medium-sized enterprises: patterns and trends. Business Strategy and the Environment, p. 1$12,2020$.

BARBIERI, J. C. Assessing the sustainability of agritourism in the US: a comparison between agritourism and other farm entrepreneurial ventures. Journal of Sustainable Tourism, v. 21, n. 2, p. 252-270, 2013.

BARBIERI, J. C. Gestão ambiental empresarial: conceitos, modelos e instrumentos. São Paulo: Saraiva, 2004.

BLANCAS, F. J.; CABALLERO, R.; GONZÁLEZ, M.; LOZANO-OYOLA, M.; PÉREZ, F. Goal programming synthetic indicators: an application for sustainable tourism in Andalusian coastal counties. Ecological Economics, v. 69, n. 11, p. 2158-2172, 2010.

BOHDANOWICZ, P. Environmental awareness and initiatives in the Swedish and Polish hotel industries - survey results. Hospitality Management, v. 25, n. 4, p. 662-682, 2006.

BONG, C.; LIM, L.; HO, W.; LIM, J.; KLEMEŠ, J.; TOWPRAYOON, S.; HO, C.; LEE, C. A review on the global warming potential of cleaner composting and mitigation strategies. Journal Cleaner Production, v. 146, p. 149-157, 2017.

BRANTSAETER, A. L.; YDERSBOND, T. A.; HOPPIN, J. A.; HAUGEN, M.; MELTZER, H. M. Organic food in the diet: exposure and health implications. Annual Review of Public Health, v. 38, n. 1, p. 295-313, 2017.

BRASIL. Ministério do Turismo. Destinos nacionais serão os mais procurados após pandemia, diz pesquisa. 2020a. Disponível em: https://www.gov.br/pt-br/noticias/viagens-eturismo/2020/05/destinos-nacionais-serao-os-mais-procurados-apos-pandemia-diz-pesquisa. Acesso em: set. 2020.

BUTLER, R. W. Sustainable tourism: a state-of-the-art review. Tourism Geographies, v. 1, n. 1, p. 7-25, 1999.

CENAMOR, I.; DE LA ROSA, T.; NÚÑEZ, S.; BORRAJO, D. Planning for tourism routes using social networks. Expert Systems with Applications, v. 69, p. 1-9, 2017.

CHAN, E.; HON, A.; CHAN, W.; OKUMUS, F. What drives employees' intentions to implement green practices in hotels? The role of knowledge, awareness, concern and ecological behavior. 
International Journal of Hospitality Management, v. 40, p. 20-28, 2014.

CHIN YANG, J. Y.; CHEN, Y. M. Nature-based tourism impacts in I-lan, Taiwan: Business managers' perceptions. International Journal of Culture, Tourism and Hospitality Research, v. 2, n. 3, p. 250-270, 2008.

CHOO, H.; JAMAL, T. Tourism on organic farms in South Korea: a new form of ecotourism? Journal of Sustainable Tourism, v. 17, n. 4, p. 431-454, 2009.

CMMAD. COMISSÃO MUNDIAL SOBRE MEIO AMBIENTE E DESENVOLVIMENTO. Nosso futuro comum. Rio de Janeiro: Fundação Getulio Vargas, 1988.

CLARO, P. B. O.; CLARO, D. P.; AMÂNCIO, R. Entendendo o conceito de sustentabilidade nas organizações. Revista de Administração, v. 43, n. 4, p. 289-300, out./dez. 2008.

COHEN, E. Authenticity, equity and sustainability in tourism. Journal of Sustainable Tourism, v. 10, p. 267-276, 2002.

COELHO, M. de F.; GOSLING, M.; GONÇALVES, C. A. Sustentabilidade e responsabilidade social corporativa como estratégia para a competitividade na hotelaria. Turismo \& Sociedade, v. 6, n. 3, p. 645-670, 2013.

DALE, M. A comparative analysis of energy costs of photovoltaic, solar thermal, and wind electricity generation technologies. Applied Sciences, v. 3, n. 2, p. 325-337, 2013.

DEDINEC, A.; MARKOVSKA, N.; RISTOVSKI, I.; VELEVSKI, G.; GJORGJIEVSKA, V. T.; GRNCAROVSKA, T. O.; ZDRAVEVA, P. Economic and environmental evaluation of climate change mitigation measures in the waste sector of developing countries. Journal of Cleaner Production, v. 88, p. 234-241, 2015.

DEMAJOROVIC, J.; MIGLIANO, J. E. B. Política Nacional de Resíduos Sólidos e suas implicações na cadeia da logística reversa de microcomputadores no Brasil. Gestão \& Regionalidade, v. 29, n. 87, p. 64-80, 2013.

DESAI, K. J.; DESAI, M. P. A theoretical study of triple bottorn line approach as a tool of reporting corporate social responsibility of an enterprise. GIRA - Global Journal for Research Analysis, v. 5, n. 6, p. 83-85, 2016.

DIAS, R.; PIMENTA M. A. Gestão de hotelaria e turismo. São Paulo: Prentice Hall Pearson Brasil, 2005.

DYATLOV, S. A.; DIDENKO, N. I.; IVANOVA, E. A.; SOSHNEVA, E. B.; KULIK, S. V. Prospects for alternative energy sources in global energy sector. IOP Conference Series. Earth and Environmental Science, v. 434, p. 12014, 2020.

EVANGELINOS, K.; HALKOS, G. Implementation of Environmental Management Systems Standards: important factors in the corporate decision-making. Journal of Environmental Assessment Policy and Management, v. 4, n. 3, p. 311-328, 2002.

FERNANDES, A. M. L.; MIRANDA, S. L. Sustentabilidade ambiental nas empresas e comunicação organizacional e stakeholders: Que relação e vantagens? Comunicação, Desenvolvimento e Sustentabilidade, v. 2, p. 101-112, 2014.

FERREIRA, D.; SILVA, P.; MADEIRA, T. F. Embalagens verdes: conceitos, materiais e aplicações. Revista Americana de Empreendedorismo e Inovação, Paranaguá, v. 1, n. 2, p. 28-39, 2019.

FONT, X.; GARAY, L.; JONES, S., Sustainability motivations and practices in small tourism enterprises in European protected areas. Journal of Cleaner Production, v. 137, p. 1439-1448, 2014. 
GELLER, H.; SCHAEFFER, R.; SZKLO, A.; TOLMASQUIM, M. Policies for advancing energy efficiency and renewable energy use in Brazil. Energy Policy, v. 32, p. 1437-1450, 2004.

GIL, A. C. Métodos e técnicas de pesquisa social. São Paulo: Atlas, 1999.

GOMES, M. A. F. Água: sem ela seremos o planeta Marte de amanhã. 2011. Disponível em: http://www.redepeabirus.com.br/redes/form/post?pub_id=86583. Acesso em: 20 fev. 2021. GOSSLING, S. New performance indicators for water management in tourism. Tourism Management, v. 46, p. 233-244, 2015.

GOSSLING, S.; PEETERS, P. Assessing tourism's global environmental impact 1900-2050. Journal of Sustainable Tourism, v. 23, n. 5, p. 639-659, 2015.

GUIMARAES, R.; FONTOURA, Y. Desenvolvimento sustentável na Rio+20: discursos, avanços, retrocessos e novas perspectivas. Cadernos EBAPE.BR, v. 10, n. 3, p. 508-532, 2012.

GUPTA, J.; VEGELIN, C. Sustainable development goals and inclusive development. International Environmental Agreements: Politics, Law and Economics, v. 16, n. 3, p. 433-448, 2016.

HADJIKAKOU, M.; CHENOWETH, J.; MILLER, G. Estimating the direct and indirect water use of tourism in the eastern Mediterranean. Journal of Environmental Management, v. 114, p. 548556, 2013.

IANNONE, R.; MIRANDA, S.; RIEMMA, S.; DE MARCO, I. Improving environmental performances in wine production by a life cycle assessment analysis. Journal of Cleaner Production, v. 111, p. 172-180, 2016.

IVANOV, D. V.; ZIGANSHIN, I. I. Eco-organic tourism as an element of the sustainable development of territories. IOP Conference Series: Earth and Environmental Science, v. 107, n. 1, p. 1-5, 2018.

JACKSON, J.; MURPHY, P. Clusters in regional tourism: an Australian case. Annals of Tourism Research, v. 33, p. 1018-1035, 2006.

JAYASOORIA, D. Sustainable development goals and social work: opportunities and challenges for social work practice in Malaysia. Journal of Human Rights and Social work, v. 1, n. 1, p. 1929, 2016.

JONES, P.; HILLIER, D.; COMFORT, D. Sustainability in the hospitality industry: Some personal reflections on corporate challenges and research agendas. International Journal of Contemporary Hospitality Management, v. 28, p. 36-67, 2016.

KALLMUENZER, A.; NIKOLAKIS, W.; PETERS, M.; ZANON, J. Trade-offs between dimensions of sustainability: Exploratory evidence from family firms in rural tourism regions. Journal of Sustainable Tourism, v. 26, p. 1204-1221, 2017.

KOROSSY, N. Do turismo predatório ao turismo sustentável: uma revisão sobre a origem e a consolidação do discurso da sustentabilidade na atividade turística. Caderno Virtual de Turismo, Rio de Janeiro, v. 8, n. 2, p. 56-68, 2008.

LAZAROIU, G.; ANDRONIE, M.; UTĂ, C.; HURLOIU, I. Trust management in organic agriculture: sustainable consumption behavior, environmentally conscious purchase intention, and healthy food choices. Frontiers in Public Health, v. 7, 2019. 
MANSOUR, H.; AL- YAHYAI, F.; HEIBA, E. The Recycling Concept in Art Education at Sultan Qaboos University-ty. Journal of Education and Social Development, v. 2, n. 2, p. 82-87, 2018.

MARTINS, A. A.; ARAÚJO, A. R.; GRAÇA, A.; CAETANO, N. S.; MATA, T. M. Towards sustainable wine: comparison of two Portuguese wines. Journal of Cleaner Production, $v$. 183, p. 662-676, 2018.

MARTINS, M. de F.; CÂNDIDO, G. A. Índice de desenvolvimento sustentável para municípios (IDSM): metodologia de cálculo e análise do IDSM e a classificação dos níveis de sustentabilidade para espaços geográficos. João Pessoa: Sebrae, 2008.

MARTINEZ, M. F.; ALVES, M. B.; PERREIRA, L. A.; BEYER, P. O. Redução do consumo de energia elétrica através de conceitos Green Building. Eletrônica de Potência, v. 14, n. 2, 2009.

MATTAR, F. N. Pesquisa mercadológica. São Paulo: Atlas, 1994.

MAZHENOVA, S.; CHOI, J. G.; CHUNG. J. International tourists' awareness and attitude about environmental responsibility and sustainable practices. Global Business \& Finance Review, v. 21, n. 2, p. 132-146, 2016.

MEBRATU, D. Sustainability and sustainable development: historical and conceptual review. Environmental Impact Assessment Review, v. 18, p. 493-520, 1998.

MINAYO, M. C. S. (org.). Pesquisa social: teoria, método e criatividade. Petrópolis: Vozes, 2001.

PADILHA, A. C. M.; DE SÁ, M. M.; RODRIGUES, R. G. Horizontes da cooperação e intercooperação na primeira rota de turismo orgânica do Brasil. In: CONGRESO INTERNACIONAL DE TURISMO RURAL Y DESARROLLO SUSTENTABLE - CITURDES, 11. Anais [...]. Universidad Nacional, Costa Rica, Sede Regional Chorotega, 2018. p. 221-236.

PEETERS, P. M.; GÖSSLING, S.; KLIJS, J.; MILANO, C.; NOVELLI, M.; DIJKMANS, C. H. S.; EIJGELAAR, E.; HARTMAN, S.; HESLINGA, J.; ISAAC, R.; MITAS, O.; MORETTI, S.; NAWIJN, J.; PAPP, B.; POSTMA, A. Research for TRAN Committee - Overtourism: impact and possible policy responses. Brussels: European Parliament, Directorate General for Internal Policies, Policy Department B: Structural and Cohesion Policies, Transport and Tourism, 2018.

POTT, C. M.; ESTRELA, C. C. Histórico ambiental: desastres ambientais e o despertar de um novo pensamento. Estudos Avançados, v. 31, n. 89, p. 271-283, 2017.

PROVOST, C.; PEDNEAULT, K. The organic vineyard as a balanced ecosystem: improved organic grape management and impacts on wine quality. Scientia Horticulturae, v. 208, p. 43-56, 2016.

RADOMSKY, G. F. W. Práticas de certificação participativa na agricultura ecológica: rede, selos e processos de inovação. Revista IDeAS, v. 3, n. 1, p. 133-164, 2009.

ROESCH, S. M. A. Projetos de estágio do curso de administração. São Paulo: Atlas, 1996.

RICCI, F.; SANT'ANA, R. Desenvolvimento turístico sustentável: o artesanato local como alternativa na cidade de Santo Antônio do Pinhal, SP. Revista Cultura e Turismo, Santa Cruz, v. 3, n. 1, 2009.

RUSCHMANN, D. Turismo e planejamento sustentável: a proteção do meio ambiente. Campinas: Papirus, 1997.

SACCHELLI, S.; FABBRIZZI, S.; BERTOCCI, M.; MARONE, E.; MENGHINI, S.; BERNETTI, I. A mixmethod model for adaptation to climate change in the agricultural sector: a case study for Italian wine farms. Journal Cleaner Production, v. 166, p. 891-900, 2017. 
SAARINEN, J.; GILL, A. M. Resilient destinations and tourism: governance strategies in the transition towards sustainability in tourism. Abingdon, UK: Routledge, 2018.

SANCHES, F. C. Turismo rural sustentável: uma análise das práticas de sustentabilidade ambiental de empreendimentos no Oeste do Paraná. 2015. 126 p. Dissertação (Mestrado em Ecossistemas e Dinâmicas Socioambientais e Tecnologias Aplicadas ao Meio Ambiente) Universidade Estadual do Oeste do Paraná, Toledo, 2015.

SCHERER, L.; FERNANCES, S. B.; BORGUETTI, R.; AJALA, R.; BOLZAN, E. A Rota Via Orgânica: turismo sustentável na inovação em ecoturismo e turismo gastronômico. In: FORUM INTERNACIONAL ECOINOVAR, 2017, 6. Anais [...]. Santa Maria: ECOINOVAR, 2017.

SEVERO, E. A.; GUIMARÃES, J. C. F.; DE DORION, E. C. H.; NODARI, C. H. Environmental sustainability and organizational performance: an empirical study in the Brazilian MetalMechanic industry. Journal of Cleaner Production, v. 96, p. 118-125, 2015.

SILVA, K. B.; MATTOS, J. B. A spatial approach for the management of groundwater quality in tourist destinations. Tourism Management, v. 79, 2020.

STANFORD, D. Exceptional visitors: dimensions of tourist responsibility in the context of New Zealand. Journal of Sustainable Tourism, v. 16, p. 258-275, 2008.

TARRANT, M.; CORDELL, H. K. Amenity values of public and private forests: Examining the value - attitude relationship. Environmental Management, v. 30, n. 5, p. 692-703, 2002.

THENG, S.; QIONG, X.; TATAR, C. Mass tourism vs alternative tourism? Challenges and new positionings. Études Caribéennes, n. 31-32, 2015.

TODD, S. L.; ANDERSON, L. S. Place attachment and perceptions of benefits generated by the future Tioughnioga River Trail Project. In: PEDEN, J. G.; SCHUSTER, R. M. (ed.). Proceedings of the $\mathbf{2 0 0 5}$ northeastern recreation research symposium. Bolton Landing, NY; Newtown Square, PA: U.S. Forest Service, Northeastern Research Station, 2005. p. 401-407.

TORTELLA, B. D.; TIRADO, D. Hotel water consumption at a seasonal mass tourist destination. The case of the island of Mallorca. Journal of Environmental Management, v. 92, n. 10, p. 2568-2579, 2011.

UNWTO. UNITED NATIONS WORLD TOURISM ORGANIZATION. Covid-19: putting people first. 2020a. Disponível em: https://unwto.org/tourism-covid-19-coronavirus. Acesso em: 18 maio 2020.

VALVERDE, N. P. Sustentabilidade local e turismo: por uma compreensão do "turismo sustentável". In: SEMINÁRIO DE PESQUISA EM TURISMO DO MERCOSUL, 4. Universidade de Caxias do Sul, Mestrado em Turismo, Caxias do Sul, RS, Brasil, 2006.

YUSOF, N.; RAHMAN, S.; IRANMANESH, M. The environmental practice of resorts and tourist loyalty: the role of environmental knowledge, concern, and behavior. Anatolia, v. 27, n. 2, p. 214-226, 2015.

ZENKER, S.; KOCK, F. The coronavirus pandemic - a critical discussion of a tourism research agenda. Tourism Management, v. 81, p. 104164, 2020.

ZU'BI, M. F.; AL-DMOUR, H.; AL-SHAMI, M.; NIMRI, R. Integrated green purchase model: an empirical analysis on Jordan. International Journal of Operations and Logistics Management, v. 4, n. 2, p. 139-151, 2015. 